\title{
A poesía galega na fin de milenio
}

\author{
TERESA SEARA
}

Este emblemático ano de 2000 que vivimos parece un bo momento para enxuizar os camiños que a poesía galega vai encetando de cara 6 novo milenio, para trazar as súas vías predominantes e observar como se consolidan os discursos principais. Hai que ter en conta que a poesía é, hoxe por hoxe, o xénero máis asentado canto á edición -só hai que observar o número de poemarios publicados e comparalo, por exemplo, co de novelas- e o que ofrece un panorama máis interesante e pródigo non só no que respecta a voces e obras senón tamén no que atinxe ás posibilidades de innovación. Neste itinerario ascendente do xénero poético teñen boa parte de responsabilidade múltiples factores como a diversificación dos espacios editoriais operada na última década, os premios literarios ou a dinámica de afianzamento que manifesta o discurso feminino ata o punto de ser a liña máis rendible na actualidade.

Conforme fenece o século, as editoriais van experimentando unha consolidación que lles permite diversificar a oferta poética. Así, desde o selo que é xa unha referencia inexcusable na década dos noventa, Espiral Maior, ata as coleccións que se afianzan co paso do tempo (caso de Esquío) e as que xorden movidas polo «éxito» da poesía no noso panorama literario (como, por exemplo, Ablativo Absoluto de Xerais), observamos un amplo abano editorial que abrangue cada vez máis espacios novos como os ocupados por Letras de Cal ou pola recentemente creada Tambo. O patrocinio destes espacios por institucións tan diversas como as Deputacións Provinciais (a da Coruña publica os volumes galardonados co Miguel González Garcés nunha colección propia e a de Pontevedra sustenta Tambo), a banca (os volumes do Premio Esquío vincúlanse a Caixa Galicia) ou editoras xa consolidadas que se abren á poesía (Xerais crea Ablativo Absoluto e Galaxia fai o propio con Dombate) non impide o nacemento de proxectos máis humildes emanados da cooperatividade: así nace Letras de Cal. A un tempo, cómpre mencionar a apertura doutros espacios, ata o de agora alleos ó libro galego, que se van facendo eco das novidades, como as Edições Tema en Lisboa ou o interese de certos selos como Huerga y Fierro ou Visor por algúns poetas na nosa lingua. 
Por outra parte, en boa medida, as editoras nútrense e sosteñen a un tempo os premios literarios que seguen a ser eventos da máxima importancia á hora de abrir as portas a novos valores e así, mentres uns certames continúan na súa dinámica habitual de masiva participación (como o Esquío, por exemplo), outros van afianzándose segundo aumenta o número de libros presentados a concurso, fenómeno claramente perceptible nos premios Concello de Carral e Francisco Añón, patrocinados ambos os dous por concellos. E a un tempo, tras do precedente que supuxeron Para saír do século ${ }^{1}$ e o número monográfico de La flama en el espejo ${ }^{2}$, comezan a aparecer os primeiros volumes antolóxicos da década animados pola difusión da nosa poesía cronoloxicamente máis próxima. Neste sentido, merece un lugar destacado a obra de César Morán Río de son $e_{\text {vento }}{ }^{3}$, unha escolma ampla e ben documentada que abrangue desde a Idade Media ata as voces máis novas e que se beneficia do acompañamento dun disco compacto onde o propio antólogo musica e canta poemas de Manuel Antonio, Rosalía, Manuel Rivas, Pilar Pallarés ou Méndez Ferrín, entre outros. Aínda que a selección omite a varios autores importantes serve para actualizar a certas voces escurecidas na historia baixo o peso das grandes plumas. Do mesmo espírito parece beber dEfecto $2000^{4}$, unha antoloxía de poetas dos noventa elaborada polo Consello de Redacción de Letras de Cal onde aparece a nómina dos vinteún autores que consideran máis relevantes. Esta escolla resulta ser, tal e como din nas «Letras limiares», a suma das subxectividades de cada un dos antólogos e así aparecen todo tipo de voces e tendencias como as representadas por Rafa Villar, Marilar Aleixandre, Estevo Creus, Emma Couceiro ou Igor Lugrís.

Distinta repercusión terán outros volumes antolóxicos que viron a luz recentemente fóra das nosas fronteiras. Focado cara ó mundo anglosaxón, en Galician Generation of the eighties ${ }^{5}$ Luciano Rodríguez dirixe a version para o inglés de algúns textos de Pilar Pallarés, Xulio Valcárcel e Ramiro Fonte. Cun abano máis amplo, preséntase o volume La poésie galicienne de 1936 a 1990 (1999), elaborado por Anxo Angueira, no que o lector francofono pode atopar autores de moi distinta idade e estética como, entre outros, Arcadio López Casanova, Alfonso Pexegueiro, Xosé María Álvarez Cáccamo, Xavier Seoane, Chus Pato, Pilar Pallarés, Miguel Anxo Fernán-Vello ou Eusebio Lorenzo Baleirón. En 1999 ve tamén a luz o derradeiro tomo da escolma de poesía galega que, dirixida por Helena Zernova, vén editando o Centro de Estudios Galegos da Universidade de San Petersburgo. Baixo o título de No limiar do novo milenio teñen acubillo, versionados para o ruso, autores que comezan a publicar a partir de 1975 como Xulio Valcárcel, Ramiro Fonte, Xavier Seoane, Xosé María Álvarez Cáccamo, etc. Finalmente, tamén en Milenio. Ultimísima poesía

\footnotetext{
1 Rodríguez, Luciano e Seara, Teresa, Para sair do século, Xerais, Vigo, 1997.

2 Castaño, Yolanda (ant.), La flama en el espejo, Editorial Praxis, México, n. ${ }^{\circ} 3,1997$.

${ }^{3}$ Edicións Xerais, Vigo, 1999.

4 Letras de Cal, Amaía, 1999.

5 Universidade da Coruña, A Coruña, 1999.
} 
española 6 aparecen, a carón de autores bascos, cataláns e casteláns, algúns poetas galegos sendo así este volume a continuación doutro titulado Poesía ultimísima ${ }^{7}$ onde xa entraran Martín Veiga e Anxos Romeo.

Co mesmo carácter de escolma pero focadas cara a obras individuais destacan neste período Madeira do meu canto/ Madera de mi canto (1986-1997) ${ }^{8}$ que recolle os versos de Luís Tosar e Billarda ${ }^{9}$ de Vicente Araguas, ambas as dúas aparecidas en edición bilingüe galego/castelá. Estes poemarios permiten 0 encontro do lector con obras xa esgotadas e constitúen unha ampla mostra do quefacer poético dos antologados. Tamén teñen carácter de antoloxía o volume Don do horizonte 10 que devén en ampla selección da poética de Xavier Seoane e Blasfemias do silencio ${ }^{11}$ que recolle a obra completa de Alfonso Pexegueiro. Por outra parte, as reedicións de obras cumio da nosa literatura como Mesteres $^{12}$ de Arcadio López-Casanova e Poesía enteira de Heriberto Bens ${ }^{13}$ de Méndez Ferrín supoñen un reencontro coa palabra de dous autores referenciais na nosa historia próxima. Do mesmo xeito, a publicación dunha ampla escolma do corpus do grupo vigués Rompente -que sae á luz en Ablativo Absoluto baixo o título de Upalás ${ }^{14}$ - axuda a recuperar textos esenciais para entender o devir da nosa poesía máis recente. Na mesma tesitura sitúase a edición da obra completa de Miguel González Garcés ${ }^{15}$, que nos permite o acceso a un dos poetas que meirande influencia tivo sobre os autores da xeración dos oitenta, así como o volume Obra poética case completa ${ }^{16}$ de María do Carme Kruckenberg e a compilación de todos os poemarios publicados ata o momento por Luís Rei Núñez baixo o título de $A$ rolda invisible ${ }^{17}$.

Sen embargo, non só as reedicións nutren o panorama poético deste tempo senón que resulta trascendental o achegamento de novas voces, a madureza doutras e mesmo a deriva desde o terreo da prosa de algunhas das propostas máis interesantes hoxe en día. Así, destaca, sobre todo, a dinámica de afianzamento que experimenta o discurso das poetas ata o punto de ser o que ofrece os froitos máis innovadores rompendo cos parámetros tradicionais e asistindo á

6 Rodrfguez CAÑAda, Basilio (ant.), Milenio. Ultimisima poesía española (antología), Ediciones Celeste/ Sial, Madrid, 2000.

7 Rodríguez Cañada, Basilio (ant.), Poesía ultimísima, Libertarias/Prodhufi, Madrid, 1997.

8 Visor, Madrid, 1998.

9 Huerga \& Fierro, Madrid, 1999.

10 Espiral Maior, A Coruña, 1999.

11 Xerais, Vigo, 2000.

12 Xerais, Vigo, 1999.

13 Xerais, Vigo, 1999.

14 Cochón, Iris e González, Helena (eds.), Upalás, Xerais, Colec. Ablativo Absoluto, Vigo, 1998.

15 Gonzalez Garcés, Miguel, Poesía, Deputación Provincial da Coruña, 1999. Edición de Luciano Rodríguez.

16 Ediciós do Castro, Sada-A Coruña, 2000.

17 Tambo, Deputación Provincial de Pontevedra, 2000. 
chegada de novos nomes como os de Marilar Aleixandre, Medos Romero, Estíbaliz Espinosa ou María do Cebreiro. A súa presencia vén engrosar a lista de mulleres poetas que ofrecen obras de interese, unha nómina que viviu un pulo extraordinario nos últimos tempos por canto houbo nel certas voces prometedoras que se afianzaron (Yolanda Castaño, Lupe Gómez ou Emma Couceiro) e apareceron novos discursos demoledores canto á súa orixinalidade (como os de Marilar Aleixandre, Emma Pedreira Lombardía ou María do Cebreiro) mentres autoras xa referenciais seguen no seu ronsel propio, caso de Helena Villar Janeiro, Eva Veiga ou Ana Romaní.

As poetas seguen nas liñas deconstructivas xa habituais nelas: relectura do mito, búsqueda da orixinalidade formal, renovación do erotismo e a súa linguaxe... Así, os poemarios publicados por Yolanda Castaño nestes anos, Delicia e Vivimos no ciclo das erofanías ${ }^{18}$, afondan na destrucción da linguaxe erótica convencional a través, no primeiro dos libros, dunha sensualidade perversa case sempre volcada de cara ó eu poético e da ruptura completa e total dos tabús que se percibe no segundo así como na búsqueda duns termos novos para plasmar o erotismo particular que estructura a obra desta autora. Hai poucos días, viu a luz Edénica ${ }^{19}$ un volume antolóxico onde o verso de Yolanda Castaño se apoia na música do disco compacto que o acompaña. Sen embargo, non é esta a única vía que se percibe no camiño de renovación do Eros por canto Olga Novo opta por explorar unha vertente telúrica onde vincularse coas antepasadas nun clima de liberdade e sensualismo moi alto na súa ópera prima, A teta sobre o sol 20 e en Amar é unha India'21. Mais, non só as autoras ofrecen propostas interesantes no terreo do erotismo e así debemos mencionar a tendencia cara á sensualidade presente nas Xeografías do sal22 de Ramón Caride Ogando. Un poemario onde a pulsión amorosa se vincula a temas como o sentimento de efemeridade, a dor existencial, a denuncia das inxustizas humanas, a búsqueda de paliativos contra o paso incontrolado do tempo, asuntos que fican nun segundo plano fronte á forza inmensa e liberadora do amor. Nunha sorte de abecedario -xogando a construír poemas en orde alfabética compostos por palabras que comezan sempre pola mesma letra- os textos dedicados exclusivamente 6 gozo erótico van deixando no libro, no seu alternar co resto de apartados, o pouso dunha vivencia plena e deleitosa onde é posible arredarse de calquera ameaza. Tamén na obra de Miro Villar Equinoccio de primavera 23 atopamos o amor como forza catártica mesturado cun certo pouso culturalista e coa denuncia social que fai destes sonetos un mural de personaxes desarraigados por máis

18 Ambos os dous publicados en Espiral Maior, A Coruña, 1998. O último deles acadou o premio Xohán Carballeira e foi tamén galardonado co Premio da Crítica Española.

19 Espiral Maior, A Coruña, 2000.

20 Reeditada por Letras de Cal, Amaía, 1999.

21 Incluído no número 2 da revista Unión Libre, 1997.

22 Deputación Provincial da Coruña, 1999. Foi accésit do premio Miguel González Garcés en 1998.

23 Colección Esquío de Poesía, Ferrol, 1998. Foi accésit do Premio Esquío en 1997 e finalista no Premio Tívoli- Europa de 1998. 
que a meirande parte deles sufra un proceso deconstructivo proximo a unha das liñas máis rendibles na estética das poetas: a ruptura do mito e das imaxes patriarcais.

Seguindo coas autoras, outra das vías máis vivas do momento é a que se encarga de reivindicar o papel das precursoras nun labor de restauración dos dereitos para a muller. Neste sentido, os procesos de auto-coñecemento do eu poético que teñen en $A r d e n^{24}$ de Ana Romaní un peso crucial non só constitúen un exercicio de afirmación persoal senón que conlevan volver os ollos á estirpe matriliñal onde se sitúan as orixes, enlazando así co colectivo feminino. $O$ recurso ás devanceiras toma forza igualmente nunha das apostas máis celebradas dos últimos tempos, a que supón o descubrimento de María do Cebreiro: $O$ estadio do espello 25 . Esta autora axúdase do símbolo do espello para artellar un libro complexo e novidoso polo que pasa unha galería de figuras femininas (unificadas todas elas baixo o nome de María), de calquera época e condición, que desempeñan diversos papeis dentro do pluriculturalismo evidente no poemario. Tamén é complexa a estructura e a linguaxe que permite a Isolda Santiago artellar os poemas de Berce das estampas ${ }^{26}$, unha obra de múltiples referencias simbólicas onde a poeta se amosa, igual que no seu primeiro libro, como unha ávida pescudadora das palabras non usuais, dos versos escuros e cheos de significados ocultos a desentrañar, das figuras femininas ignotas que poboan os textos cun arrecendo a pasado e a historia.

Doutro signo son as obras que ofrecen neste momento Anxos Romeo e Lupe Gómez. A primeira, en Ollos de sal27, segue explorando temáticas e linguaxes claramente vinculadas ó cripticismo ó tempo que recorre a unha ambientación desértica para expresar graficamente a forza lacerante do sal. Neste entorno, habitado por un bestiario simbólico moi particular, o eu inicia un camiño de retrospección que o leva a fuxir da cruel realidade deste ámbito mediante visións parabólicas e elipses explicativas. Pola súa parte, Lupe Gómez retoma, tanto en Os teus dedos na miña braga con regra como en Poesía $\mathrm{fea}^{28}$, as formas breves e concisas que xa primaban no seu primeiro poemario para seguir afondando na súa poética da distorsión e revisión dos modelos femininos patriarcais e das estratexias de auto-representación. De novo, as putas e as nenas aparecen como exemplos de rexeitamento social ou seres sometidos a unha moral restrictiva que é preciso dinamitar $\sigma$ tempo que se artella unha triple corrente transgresora que afecta á linguaxe, á ruptura cos arquetipos tradicionais e á presencia no texto dos procesos fisioloxicos femininos como reivindicación da outredade, da diferencia. Algo parecido acontece en Setembro 29 de Marta Dacosta onde se establece un fío directo coa xinea de

24 Espiral Maior, A Coruña, 1998.

25 Xerais, Colec. Ablativo Absoluto, Vigo, 1998.

26 Espiral Maior, A Coruña, 1998.

27 Xerais, Vigo, 1999.

28 Xerais, Colec. Ablativo Absoluto, Vigo, 1999 e Noitarenga, Santiago, 2000, respectivamente.

29 Galaxia, Colec. Dombate, Vigo, 1998. Foi Premio Martín Codax. 
mulleres que preceden 6 eu poético a través da experiencia compartida da maternidade e tamén co propio fillo como creatura que fai consciente 6 eu da súa natureza máis oculta. Nesta búsqueda, acábase asumindo o postulado Beauvoireano de que a condición feminina só pode cultivarse desde a reivindicación da diferencia, unha reivindicación que se acentúa en En atalaia alerta ${ }^{30}$, onde a autora adopta un ton confesional que non disimula o radical vitalismo de quen se amosa totalmente espido nos versos.

O exercicio deconstructivo de modelos femininos tradicionais está tamén presente no volume con que se nos revela o labor poético de Marilar Aleixandre. Descuberta da man do premio Esquío, esta recoñecida narradora recolle en Catálogo de velenos ${ }^{31}$ a estela doutras conxéneres e ofrece unha nova versión da Brancaneves dos relatos infantís que, enfrontada á madrasta, debe sortear unha serie de diferentes ameazas 6 longo da súa vida, un catálogo de velenos que lle furtan o desenvolvemento da súa verdadeira identidade. Mais esta Brancaneves non é o personaxe submiso dos contos de fadas senón que rompe coa imaxe feminina tópica para asumir uns moldes comportamentais máis igualitarios que deveñen nun exercicio de libre albedrío pola súa parte. Na súa última edición, o premio Esquío revelounos a voz de Estíbaliz Espinosa quen indaga, en $\operatorname{Pan}^{32}$, sobre as orixes do entorno e das creaturas adoptando unha forma sintacticamente anárquica que a leva a subverter a orde habitual dos termos e a romper coa linealidade do verso. $O$ mesmo tempo, o manexo pola súa parte dun complexo aparello simbólico vaina achegar á poética que nos ofrece Emma Pedreira Lombardía en Diario bautismal dunha anarquista morta 33 onde a pegada da filosofía de raíz comunista e anarquista se mestura cunha prodigalidade expresiva case abafante que roza o cripticismo. Así, nos seus versos subordínase a pulsión amorosa ós principios da anarquía comunal que fai estar sempre presente a un nós colectivo aínda por riba desa unidade que forman o eu e o ti.

Dun cariz totalmente oposto é a liña intimista e desolada que predomina na segunda obra de Emma Couceiro: As entrañas horas ${ }^{34}$ onde o proceso de autocoñecemento leva 6 eu poético a desdobrarse en figuras simbólicas como a iniciada ou Andra (con fondas reminiscencias das agardadoras e encerradores presentes no seu primeiro poemario). Volven outravolta 6 verso desta autora os ámbitos abafantes e complexos, cheos de perigos e ameazas que o ser debe percorrer á procura dunha saída positiva e así esta visita ó fondo de si mesma non implica unha viaxe gozosa por canto a catarse parte sempre da destrucción. Nesta liña de proximidade cara 6 íntimo debemos situar tamén os exercicios retrospectivos propostos por Helena Villar Janeiro en Álbum de fotos 35 , unha serie de poemas escritos sobre as fotografías dun álbum familiar constatando os

\footnotetext{
30 Colección Esquío de Poesía, Ferrol, 2000. Esta obra acadou do Premio Esquío en 1999.

31 Colección Esquío de Poesía, Ferrol, 1999. Foi Premio Esquío en 1998.

32 Colección Esquío de Poesía, Ferrol, 2000.

33 Espiral Maior, A Coruña, 1999. Acadou o premio Johán Carballeira.

34 Ediciós do Castro, Sada-A Coruña, 1998. Foi Premio Eusebio Lorenzo Baleirón en 1997.

35 Espiral Maior, A Coruña, 1999.
} 
cambios provocados polo tempo sobre os seres e as cousas a través dun verso fluído e da palabra concisa. Doutra xinea é a pegada intimista presente en $\mathrm{Luz}$ de facer memoria 36 de Manuel Álvarez Torneiro quen recorre ó seu leit-motiv principal, a memoria, para artellar un poemario de gran intensidade e estética moi coidada. A forza da memoria aseméllase á da luz -iniciática e vivificantepois permite superar a ameaza sempre latente que imprime o tempo sobre todos os seres e esquecer as horas escuras e abafantes en que o ser se sentía ameazado polas circunstancias vitais e políticas que lle toca vivir. Nesta mesma tesitura hai que situar o recurso á evocación do pasado en Balsaín blues ${ }^{37}$ de Domingo Tabuyo, unha obra de matriz elexíaca polo pai morto.

Pola súa parte, o pouso existencial sobrancea nos poemas que compoñen Paisaxes do baleiro 38 o segundo e agardado libro de Eva Veiga que constitúe a crónica do enfrontamento do ser coa morte, unha batalla que se asume con aceptación calma e resignada pois este é un inevitable proceso que achega 6 ser á súa esencia. $O$ óxido e os lirios son os elementos simbólicos primordiais que reflecten a un tempo a sensación demoledora de ir perdendo a vida e o achegamento cara á brancura total, ese estadio de lucidez onde se percibe nitidamente o canto cósmico e vitalista que entona a natureza.

Dentro da liña que pretende subverter as fronteiras intraxenéricas, Alfonso Pexegueiro ofrece en Hipatía ${ }^{39}$ unha obra onde cuestiona, atribuíndo o valor universal a un suxeito feminino, as marcas da identidade xenérica. $O$ texto ofrece múltiples lecturas -existencial, feminista, política, mítica e dramática-ó tempo que propón unha vía nova no enfrontamento do binomio patriarcal: masculino dominante (representado nos poemas por René Char) fronte 6 feminino sometido (Hipatía). Estes mesmos trazos aparecen en Pronomes 40 de Antón Lopo onde o corpo e o sexo se converten en formas de auto-coñecemento, aceptación e constatación gozosa da realidade máis escondida de cada un. Así, hai que asumir as peculiaridades do corpo rexeitando calquera condicionamento biolóxico ou cultural e mesmo os comportamentos regrados. Outra obra novidosa é a ópera prima de Claudio Pato: $O$ almorzo do pintor de iconos Andrei Rublev ${ }^{41}$, un poemario críptico que destrúe a orde habitual da linguaxe e que se amosa moi rupturista cos convencionalismos mentres indaga na historia e nas súas contradiccións.

Noutra orde de cousas destacan as obras de Lino Braxe e Eduardo Estévez. Este último en Lúa gris 42 asume o feitío dun poeta flaneur mentres percorre

36 Deputación Provincial da Coruña, A Coruña, 1999. Foi Premio Miguel González Garcés en 1998 e Premio da Crítica Española 1999.

37 Concello de Ourense, Ourense, 1998. Acadou o Premio Cidade de Ourense en 1997.

38 Xerais, Colec. Ablativo Absoluto, Vigo, 1999.

39 Xerais, Colec.Ablativo Absoluto, Vigo, 1998.

40 Espiral Maior, A Coruña, 1998.

41 Xerais, Colec. Ablativo Absoluto, Vigo, 1998.

42 Xerais, Colec. Ablativo Absoluto, Vigo, 1998. 
diferentes espacios vitais amosando unha querencia polo detalle que é común a Lino Braxe en $O$ sangue dos árabes ${ }^{43}$. Nesta nova obra afonda Braxe na tradición poética oriental, manténdose así na xinea que xa iniciara en poemarios anteriores e que lle permitiron dar vida a unha experiencia poética multidisciplinar titulada «O ouro das tribus»44. Nela, a mestura de versos de Omar Kayyam, haikus xaponeses e o espectáculo poético-musical A caricia da serpe coa creación en vivo dun mural por parte do pintor Correa Corredoira constituíu un precedente para os Poemas obxecto e visuais 45 que presentou hai poucos meses na Universidade da Coruña. Nesta mesma liña oriéntase a performance que construíron Ana Romaní e Antón Lopo en $L o b^{*} s$ mesturando textos propios de Arden e Pronomes e conxugándoos con poemas doutros autores como Manuel Outeiriño, Pilar Beiro ou Xabier Cordal. Nunha dimensión máis minoritaria pero igualmente interesante móvense as experiencias da Corporación Semiótica do Salnés que dá á luz varios volumes de poesía visual: De-funcionario, SPOT e Publipoemas ${ }^{46}$ onde texto e imaxe conviven a diferentes niveis buscando a plurisignificación total. Máis convencionais resultan as propostas de Carlos Negro en As laranxas de Alí Babá47, onde se aproxima ós contos populares e á literatura xuvenil mediante a prosa poética; Medos Romero en Rendéome no tempo e Ámome en por $\min ^{48}$ cuns versos asulagados de referencias paisaxísticas a un entorno harmonioso e apacible ou X.C. Gómez Alfaro, autor dun poemario de matriz relixiosa: Ofertorio de solpores 49 . Tamén entre os volumes curiosos cómpre destacar igualmente a obra póstuma de Ramón Sampedro, Cando eu caia ${ }^{50}$, onde pide para si a eutanasia, práctica que defende no poemario.

A finais de 1998 presentouse o número cero dunha revista artesanal dirixida por Yolanda Castaño e Olga Novo co nome de Valdeleite. Esta experiencia que se sae dos moldes convencionais para este tipo de productos canto a forma (está composta por unhas follas de cores fotocopiadas e postas dentro dunha bolsa de veludo) e concepción (pretende ser un referente libertario nesta fin de século) ten carácter anual aínda que, de momento, non temos noticia da publicación do número un. Súmase así esta canle a outras que tamén se abren cara á expresión poética como as xa consolidadas Unión Libre, Dorna ou Clave Orión.

Un dos fenómenos máis esperanzadores dos producidos nos últimos tempos é a apertura gradual que se vai dando nos territorios irmáns de Portugal de

43 Xerais, Colec. Ablativo Absoluto, Vigo, 1999.

44 Tivo lugar na galería «Atlántica» da Coruña o 12 de agosto de 1999. Os textos de A caricia da serpe viron a luz en Espiral Maior, Colec. Illa Verde, A Coruña, 1999.

45 Espiral Maior, A Coruña, 1999.

46 Todos eles aparecen en edición de autor en 1998, o primeiro, e 1999 os outros dous.

47 Letras de Cal, Amaía, 1998.

48 Edición da autora, 1998 e Espiral Maior, A Coruña, 1999, respectivamente.

49 Espiral Maior, Colec. A illa verde, A Coruña, 1999.

so Xerais, Vigo, 1998. 
cara á nosa literatura e, sobre todo, respecto á poesía. Así o constata, por exemplo, a organización dunha velada poética con Rafa Villar, Marta Dacosta e Yolanda Castaño na cidade do Porto en 1999 ou a presencia de varios autores galegos (Mónica Góñez, Chus Pato, Luísa Villalta, Xosé María Álvarez Cáccamo, Rafa Villar, Yolanda Castaño ou María Lado) no Festival «Esta 2000» celebrado na localidade de Estarreja na última semana de maio deste ano. Nesta apertura é crucial o labor de Carlos Saraiva Pinto e Alberto Augusto Miranda que organizan e promoven actividades de diverso tipo en relación coas nosas letras. $\mathrm{O}$ último deles tamén ten publicado no selo Edições Tema varias obras en galego como as prosas poéticas, vinculadas co surreal, de Anxo Pastor en $O$ cavalo económico-Sombra fértil 51 ou o volume Mulher a facer vento 52 onde conviven os poemas de sete autoras galegas. Deste xeito, no libro atopamos o surrealismo críptico de Anxos Romeo alternando coa denuncia social de Luz Pozo Garza, a pulsión erótica transgresora omnipresente en Yolanda Castaño, o intimismo de Emma Couceiro, a musicalidade extrema de Luísa Villalta, o telurismo revestido en sensualidade nos poemas de Olga Novo e a viaxe introspectiva de Ana Romaní polas rúas de Lisboa. Máis recentemente, este selo abre as súas páxinas a Rafa Villar quen afonda, en Ícaro ${ }^{53}$, na liña de contención lingüística que vén explorando desde Casa ou sombra, nesa «poesía do silencio» onde a palabra se recolle en si mesma recurrindo á plurisignificación, á espidez estructural, algo que non lle furta ó verso, porén, unha profundidade filosófica de matriz idealista. O personaxe mitolóxico de Ícaro inmerso na contradicción entre os seus altos desexos e os nefastos froitos obtidos da súa aventura vai ser o elemento omnipresente nestes poemas. Pola contra, Ana Santorum Ardone adopta en Espacio virtual ${ }^{54}$ un ton derrotado moi próximo á búsqueda de algo que se perdeu e non se sabe onde pode estar, algo inacadable do que nin sequera se coñece a súa natureza. Esta procura pon en contacto $6 \mathrm{eu}$ poético cunha atmosfera alucinada onde os fantasmas, os sudarios e certo xinete estraño que se pasea polos versos nos levan cara a unha cidade misteriosa, arrabaleira e decadente, que resulta cruel para a voz lírica.

Apostando claramente pola descuberta de novas voces, Letras de Cal ofrece de cando en vez novos títulos nos que se pon de manifesto esta filosofía. Así, Sechu Sende propón en Odiseas 55 unha relectura dos mitos clásicos grecolatinos e da viaxe de Ulises mentres que Paco Souto establece, en Fado56, unha relación directa entre o verso espido e esta forma musical tan cercana á tristeza e 6 desgarro. Na mesma liña de dar canle ás novas voces participan os cadernos da colección O Roibén que comezan a ser editados en Madrid en 1998. A súa primeira e

51 Edições Tema, Lisboa, 1998. Contamos cunha edición de 1999 en Espiral Maior baixo o título de Sombra fértil.

52 Edições Tema, Lisboa, 1998.

53 Edições Tema, Lisboa, 1999.

54 Edições Tema, Lisboa, 1999.

55 Letras de Cal, Amaía, 1998.

56 Letras de Cal, Amaía, 1998. 
máis interesante mostra é o volume colectivo Comercial $^{57}$ que recolle textos de todos os integrantes do grupo Bilbao, escritores galegos que viven en Madrid como Vicente Araguas, Xavier Frías, Crisanto Veiguela, Claudio Pato ou Fermín Bouza.Outros títulos desta colección son os colectivos Carreiros 58 e Xeitos de falar ${ }^{59}$, ambas as dúas mostras de poesía asturiana -en galego a primeira e en asturiano a segunda-, así como Xábregho, opúsculo individual de Carlos Solla.

A consolidación de voces nestes últimos anos pasa tamén polas obras, de moi distinto teor, que dan 6 prelo autores xa consagrados no noso sistema literario. Deste xeito, a edición por parte de Espiral Maior da obra completa de Xavier Seoane baixo o título de Don do horizonte permite ós lectores o acceso ó corpus total deste autor, tan relevante durante a década dos oitenta por supoñer un dos piares básicos á hora de falar da renovación poética emprendida nesa altura. E, aínda máis, ofrece unha boa mostra de textos inéditos. Outra das voces clave neste momento é a de Cesáreo Sánchez Iglesias quen segue, en Evadne ${ }^{60}$, na súa liña de contención propia e indaga no amor e na espidez inherente a quen ama. Por outra parte, o volume póstumo de Fiz Vergara Vilariño: Animal sen fel61 constitúe unha sorte de testamento poético a través duns textos fondamente sentidos que teñen como protagonista a un animal, o can, arquetipo da fidelidade sen condicións, a quen o autor dedica os seus sonetos. Nunha tesitura máis social e comprometida móvense Os cadernos da ira62 de Xosé María Álvarez Cáccamo, magnífico exemplo de poesía combativa onde a memoria máis dolorosa penetra no verso para apousar nel. Así, o autor ofrece reunidos tres opúsculos - «Prego de cargos» (1991), «De mañá que medo» (1993) e "Crónica do espanto» (1998)cun vínculo común que é o desexo de deixar clara a postura activa perante as inxustizas sexan estas moi próximas no tempo ou ben se desloquen ata o escuro espacio da guerra civil co seu espanto e crueldade incomprensibles.

Fronte a esta liña de tendencia épica cabe destacar a deriva cara 6 culturalismo sempre presente en Paulino Vázquez que o leva no seu último libro, $A$ experiencia inglesa ${ }^{63}$, a revisar os modelos da literatura anglosaxona finisecular como homenaxe ós autores amados. Desta maneira pode verse tamén a obra de Ramiro Fonte Mínima moralidade 64 , un conxunto de poemas -logo incluídos en Capitán Inverno65 - onde se asumen os postulados presentes nas moralia de Adorno e nas máximas filosóficas que o obrigan a volver os ollos á socie-

57 Edicións Río Xubia, Colec. O Roibén, Neda, 1998.

58 Conde, Adela; Veiguela, Crisanto e Frias, Xavier, Carreiros (Mostra de poesía da Terra Eo-Navia en lingua galega), Edicións Río Xubia, Colección O Roibén, Neda, 1998.

59 Piñán, Berta; González, Humberto e Velázquez, Alfonso, Xeitos de falar (Mostra de poesía asturiana), Edicións Río Xubia, Colección O Roibén, Neda, 1999.

60 Espiral Maior, A Coruña, 1998.

61 Espiral Maior, A Coruña, 1999.

62 Espiral Maior, A Coruña, 1999.

63 Edición de autor, 1998.

64 Deputación da Coruña, A Coruña, 1998. Foi Premio González Garcés 1997.

65 Xerais, Vigo, 1999. 
dade na que vivimos para extraer dela unha mensaxe ética desoladora. Pola súa parte, Capitán Inverno, composto polos anteriores poemas a quen se acrecentan varios apartados máis, supón unha volta á cidade natal, ó pasado, ós cines da infancia para reencontrar 6 neno que se foi no home que se é agora marcado pola experiencia vital e polos avatares sufridos. De diferente signo é a viaxe que propón Rafael Lema en Atlántida ${ }^{66}$ pois, volvendo 6 ámbito do mar que lle é tan caro, este autor ofrece unha singradura intimista e desolada que lle serve como elemento constructivo dun poemario complexo e ricaz nas súas connotacións que segue a amosar unha fonda pegada manuelantoniana.

Nestes últimos anos hai que constatar igualmente a chegada de varios narradores á poesía, feito que, para algúns, significou o reencontro cun xénero que xa cultivaran como Francisco Fernández Naval con Días de cera67 -magnífico poemario onde se indaga, a través do símbolo da cera, sobre a fraxilidade da vida poboada de aves que cantan e marchan- ou Xosé Carlos Caneiro con Ainda soñas con piratas?68, un cento de poemas de amor breves e espidos. Porén, para outros, representa a súa primeira incursión no terreo da lírica, é o caso de Alfonso Álvarez Cáccamo que constrúe en $\mathrm{Na}$ flor do vento ${ }^{69}$, un poemario onde a memoria e a falta dos seres queridos permiten artellar un discurso melancólico pero 6 mesmo tempo sensual no recordo do amor.

Canto a un dos fenómenos máis característicos da década dos noventa, o que se refire á proliferación de grupos e colectivos poéticos, hai que lamentar o esmorecemento do Batallón Literario da Costa da Morte, o grupo que levou a poesía ós lugares máis variopintos e un dos referentes colectivos máis importantes nesta fin de século. O Batallón despídese cun volume que reúne os versos dos seus distintos membros do mesmo con textos de poetas da cidade cubana de Holguín englobados por un intenso e fermoso introito de Xosé Neira Vilas. Así, Mar por medio 70 vén supoñer a despedida deste proxecto de dinamización da palabra a través de recitais poéticos, encontros de escritores e volumes antolóxicos que nos permitiu descubrir algunhas das voces máis frescas dos últimos anos (María Lado, Estevo Creus, Mónica Gónez, Modesto Fraga, etc.). Mais este espírito de unión colectiva para dinamizar a palabra directa non esmorece senón que se consolida no caso do grupo Sete Naos que ofrece en 1998, desde Cambados, o seu primeiro volume colectivo co mesmo nome que o grupo e onde participan voces como as de Iria Peiteado, Irene Cacabelos ou Tareixa Abal, que xa van sendo habituais na nómina de gañadores dos distintos certames. Igualmente, o colectivo poético coruñés Humilladoiro centra o seu labor en organizar actos de diverso tipo e en editar a folla voandeira «Polpa». Un fenómeno este das follas voandeiras estensible a outras como as patrocinadas polo Colectivo Sacou en Noia («A Caramuxa») ou as que nacen do esforzo individual, caso de «A Escolma» editada por Alberte Monán.

66 Espiral Maior, A Coruña, 1999. Acadou o Premío Concello de Carral en 1998.

67 Espiral Maior, A Coruña, 1999.

68 Espiral Maior, A Coruña, 1999.

69 Espiral Maior, A Coruña, 1999.

70 Concello de Corcubión/Batallón Literario da Costa da Morte, 1998. 
A proliferación dos actos arredor da poesía segue unha progresión ascedente e algún deles dá pé a experiencias tan interesantes como a que recolle o volume Novas voces da poesía galega 71 . Nel os textos acompáñanse dun disco compacto onde se pode escoitar a voz dos seus autores de xeito que estas pasan xa a formar parte do Arquivo Sonoro de Galicia patrocinado polo Consello da Cultura Galega. Son dez os poetas que recitan: Yolanda Castaño, Estevo Creus, María do Cebreiro, Ana Romaní, Celso Fernández Sanmartín, Marta Dacosta, Martín Veiga, Olga Novo, Emma Couceiro e Rafa Villar. Outra experiencia colectiva de dinamización da palabra poética especialmente relevante foi a que reuníu, co título de « 24 horas de poesía», a multitude de creadores e lectores no Teatro Rosalía da Coruña durante todo un día en marzo deste mesmo ano. E, xa a menor escala, as cinco horas de lectura poética con que se celebrou o aniversario do Forum Metropolitano en abril.

Finalmente, cabe destacar que o aumento progresivo na publicación de poemarios vai en consonancia cun meirande interese da crítica por esta manifestación literaria. Así medra o número de artigos e reseñas sobre obras recentes e comezan a aparecer tamén os primeiros estudios xerais e de conxunto sobre a última época. Neste sentido, sobrancea o volume Anatomía da emoción poética 72 onde Fidel Vidal recolle unha serie de traballos sobre autores de distintas épocas, predominando os pertencentes á xeración dos oitenta. Tamén as revistas se institúen como vehículos adecuados para a difusión e reflexión poética, ben incluíndo seccións periódicas orientadas a dar conta das novidades, ben publicando números monográficos. Entre estes figura o que Grial dedica á poesía escrita entre 1985-199873 onde se ofrece unha escolma de textos complementando as reflexións de diversos críticos sobre os aspectos máis relevantes das obras publicadas entre eses anos.

Por tanto, este repaso somero polo acontecido no terreo da poesía durante os últimos anos da década dos noventa oriéntanos cara unhas conclusións abertas e integradoras que pasan por asumir que é tal a cantidade de propostas e voces interesantes que non resulta posible establecer unhas pautas ríxidas aplicables a este momento. Así, percíbese xa a consolidación de diversas propostas que nos chegan a través de medios diferentes pois cada vez é máis nítida a presencia do audiovisual e a tendencia cara á multidisciplinariedade. Igualmente, destaca a superposición de liñas e estéticas, ás veces, incluso dentro dun mesmo autor o que provoca unha sensación de estrañamento do lector perante o producto que se lle ofrece. Obsérvase porén que a poética avanza cara á diversificación de modelos, cara á heteroxeneidade máis complexa, algo que converte a esta época nunha das máis ricas e intensas da nosa historia literaria e algo que fornece a calquera lector dunha poética á súa medida. Non hai máis que deixarse mergullar na aventura dos versos.

71 Consello da Cultura Galega, Arquivo Sonoro de Galicia, Santiago, 2000.

72 Ediciós do Castro, Sada-A Coruña, 2000.

73 Grial, 140, 1998. 